\title{
Ultrasound-guided superior laryngeal nerve block - A description of the technique
}

\author{
Bloqueo de nervio laríngeo superior guiado por ecografía. \\ Descripción de la técnica
}

\section{Yulian Camilo Echeverri-Ospina ${ }^{a-c}(\mathbb{D})$, Mario Andrés Zamudio Burbano ${ }^{c}(\mathbb{D})$, Daniela González Giraldoc (iD)}

\author{
a IPS Universitaria Clínica León XIII. Medellín, Colombia

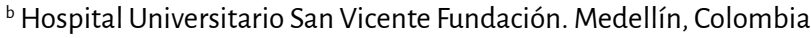

' Facultad de Medicina, Universidad de Antioquia. Medellín, Colombia

Corresponding author: Calle 69 \# 51C-24, IPS Universitaria Clínica León XIII. Medellín, Colombia. E-mail: yulian.echeverry@udea.edu.co

How to cite this article: Echeverri-Ospina YC, Zamudio Burbano MA, González Giraldo D. Ultrasound-guided superior laryngeal nerve block - A description of the technique. Colombian Journal of Anesthesiology. 2021;49(1):e939.

\section{Abstract}

Complications in airway management remain a common cause of anesthesia-associated mortality. When a patient is considered with anticipated difficultairway, the management depends on several variables, however, at present, the standard of management continues to be the patient awake approach. In scenarios of acute upper airway obstruction, the only way to guarantee adequate ventilation is to obtain a translaryngeal or transtracheal access, for which, it is necessary to use local anesthesia and grade I/ II sedation, avoiding loss of spontaneous ventilation. For this purpose, we propose ultrasound-guided superior laryngeal nerve block, in order to standardize an ultrasound landmark that is reproduceable, with a high success rate, which allows limiting complications related to regional anatomic techniques and thus facilitating the securing of the airway in these patients.

\section{Palabras clave}

Ultrasound; airway obstruction; local anesthesia; laryngeal nerve; nerve block.

\section{Resumen}

Las complicaciones en el manejo de la vía aérea siguen siendo una causa frecuente de mortalidad relacionada con anestesia. Cuando un paciente se considera con vía aérea difícil anticipada, el manejo depende de diversas variables, sin embargo, en la actualidad, el estándar de manejo sigue siendo el abordaje con paciente despierto. En escenarios de obstrucción aguda de la vía aérea superior, la única forma de garantizar una adecuada ventilación es obtener un acceso translaríngeo o transtraqueal, para lo cual, es necesario el uso de anestesia local y de sedación grado I/Il evitando la pérdida de ventilación espontánea. Con este propósito, planteamos el bloqueo del nervio laríngeo superior guiado por ultrasonografía, con el fin de estandarizar una referencia ecográfica reproducible, con alto índice de éxito, la cual permita limitar complicaciones relacionadas con las técnicas regionales anatómicas y así facilitar el aseguramiento de la vía aérea en estos pacientes.

\section{Palabras clave}

Ultrasonografía; obstrucción de las vías aéreas; anestesia local; nervios laríngeos; bloqueo nervioso.

\section{INTRODUCTION}

The difficult airway is a challenge for the anesthesiologist. Notwithstanding the advances made in airway management, between 26 and $64 \%$ of anesthesia- associated perioperative deaths are the result of airway problems. $(1,2)$ When a patient presents with anticipated difficult airway, the strategies can be varied, depending on the clinical context, the available resources, and the level of training of human resources. However, most clinical practice guidelines agree that difficult airway management shall be approached with the patient awake.

Intubating the patient awake improves the perioperative safety, since it allows for 
spontaneous breathing, maintaining the patency of the airway, and cooperation with the operator. $(3,4)$ The flexible fiber optic technique is the most commonly used by anesthesiologists; however, other strategies have emerged as an alternative, such as video laryngoscope-assisted intubation with the patient awake. (5)

In situations of an acute upper airway obstruction, the only way to ensure adequate ventilation is a translaryngeal or transtracheal approach. Since the standardization of the technique, elective tracheostomy has been broadly discussed in the literature, and compared to other methods, such as elective cricothyroidotomy, has proven to be safer. When the anesthesiologist considers this technique as the first choice, local anesthesia of the airway and grade $\mathrm{I} / \mathrm{II}$ sedation are a pressing need in order to conduct a safe procedure, without losing spontaneous ventilation. (6)

Several techniques have been described to administer upper airway anesthesia, in order to do an awake intubation in patients with anticipated difficult airway. The objective of the ideal technique is the use of the lowest possible dose of the local anesthetic agent, to achieve a successful block that facilitates the intubation conditions, and increases the safety and tolerability of the patient. Ultrasound as a tool for superior laryngeal nerve block has several advantages: first, to standardize an ultrasound landmark that is reproduceable for the operator performing the technique, ensuring the successful injection of the local anesthetic and the spread into the target nerve. Second, to avoid puncturing vascular structures and reduce the risk of intoxication with local anesthetics. Third, to reduce the likelihood of failed blocks, as compared to techniques using anatomic landmarks, by visualizing the needle and the spread of the anesthetic into the indicated landmark.

Following is a description of an ultrasound-guided technique to block the internal branch of the superior laryngeal nerve (ibSLN).

\section{SENSITIVE INNERVATION OF THE LARYNX}

The sensory information of the larynx is transmitted by the vagus nerve. Just above the greater hyoid horn, the superior laryngeal nerve divides into the external and internal laryngeal branch. The latter transmits the sensory stimulus of the upper mucosa of the vocal folds, the posterior mucosa of the epiglottis, the folds of the arytenoids and the base of the tongue. The rest of the sensory information of the larynx (glottis, cricothyroid membrane, and tracheal mucosa) are the responsibility of the internal laryngeal branch of the recurrent laryngeal nerve. Both internal laryngeal branches (of the recurrent and the superior laryngeal nerves) join just below the grater horn of the hyoid bone, to form Calen's loop (7) (Figure 1).

FIGURE 1. Sensory innervation of the larynx and trachea.

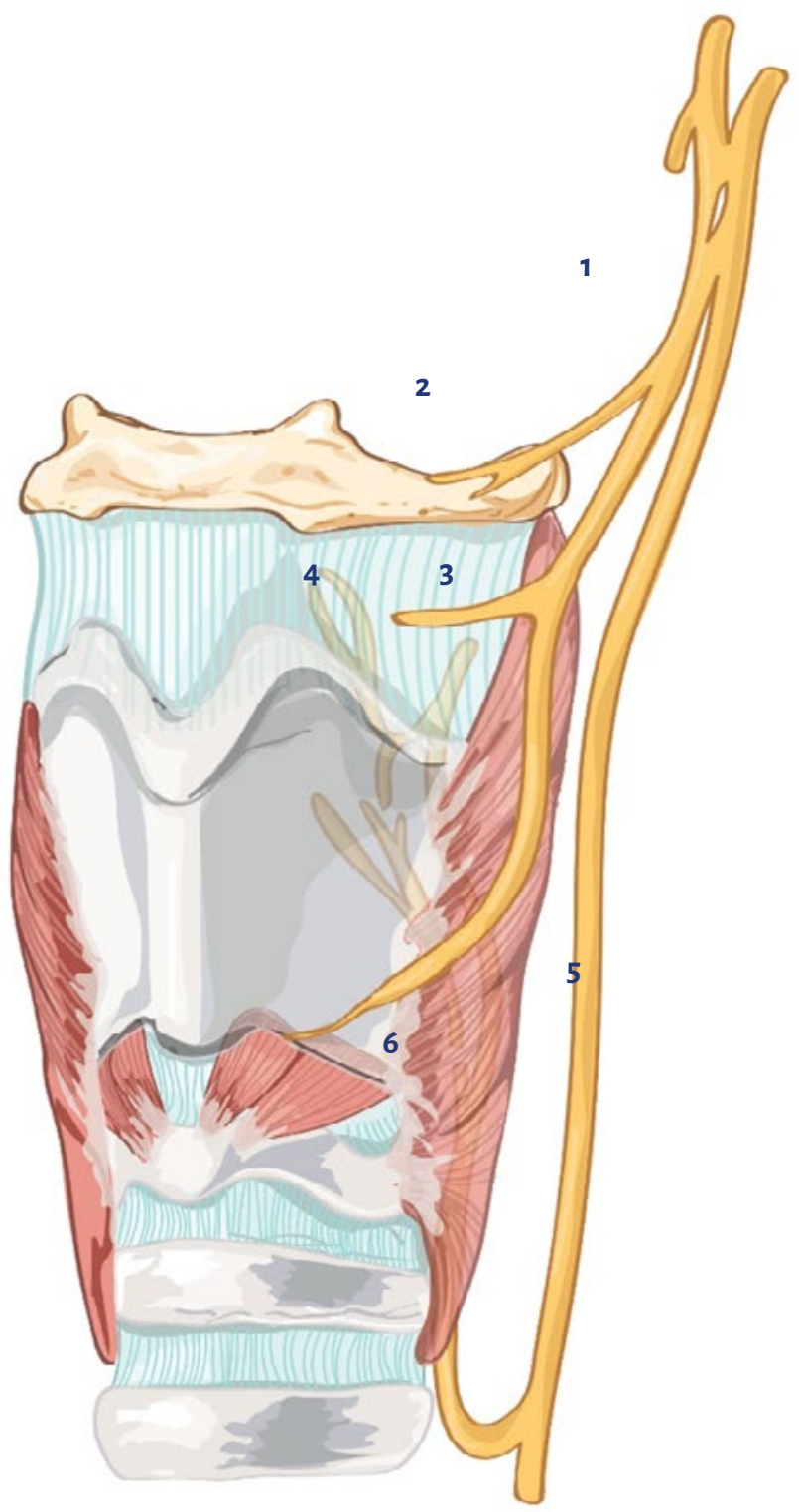

(1) Superior laryngeal nerve; (2) external branch of the superior laryngeal nerve; (3) internal branch of the superior laryngeal nerve; (4) Galen's loop; (5) recurrent laryngeal nerve; (6) internal branch of the recurrent laryngeal nerve. SOURCE. Authors. 


\section{ULTRASOUND GUIDED LARYNGEAL BLOCK}

Anatomic landmark-guided airway block may be difficult in some patients with altered anatomy, obese patients, or patients with short necks. With the advent of perioperative ultrasound, identifying and assessing the laryngeal structures has become easier, which allows for guiding the sensory nerve block of the larynx to achieve translaryngeal access.

Stopping the neural afferent transmission of the larynx is possible by blocking the internal branch of the superior laryngeal nerve and the internal branch of the recurrent laryngeal nerve with local anesthetic.

\section{DESCRIPTION OF THE ULTRASOUND-GUIDED SUPERIOR LARYNGEAL NERVE BLOCK}

Using the high-frequencyultrasound probe located in the submandibular area and paramedial in a cephalocaudal direction, the laryngeal structures can be identified: the greater horn of the hyoid bone, the omohyoid muscle, the sternohyoid muscle, and the thyrohyoid membrane. Figure 2 illustrates an ultrasound window which allows for standardization of the block technique. Once the three infrahyoid muscles and the grater horn of the hyoid bone have been identified, using the offplane approach, a hypodermic $23 \mathrm{C}$ needle is inserted and $1 \mathrm{~mL}$ of $2 \%$ lidocaine is injected between the muscle and the thyrohyoid membrane; in order to block the internal branch of the superior laryngeal nerve, a bilateral puncture is performed.

The transtracheal administration of the local anesthetic ( $3 \mathrm{~mL}$ of $2 \%$ lidocaine) between the thyroid cartilage and the cricoid ring, anesthetizes the laryngeal and tracheal mucosa, blocking the internal branch of the laryngeal recurrent nerve.

This ultrasound window allows for adequate reproducibility and successful ibSLN block. First, it enables the standardization of an image by identifying the three infrahyoid muscles, the hyoid and the thyrohyoid membrane, to reach the ibSLN space. Second, visualization of the ibSLN under ultrasonography has been reported as technically challenging, in part because of the small nerve diameter; hence, unexperienced operators may use the guide of the landmarks described for a successful block. (8)

The possibility to perform an ultrasound-guided ibSLN block can be evidenced using a fresh cadaveric model. A high frequency probe was used located paramedial to the larynx, and after identifying the suggested ultrasound window, $1 \mathrm{~mL}$ of methylene blue was injected into the space of the ibSLN. After the anatomic dissection, Figure 3 shows the methylene blue spread over the thyrohyoid membrane and the ibSLN. This confirms the performance of the ultrasound-guided approach to block the ibSLN.

The importance of the ultrasoundguided superior laryngeal nerve block is because it facilitates a sensory block while preserving the motor function of the larynx, maintaining the patency, and protecting the airway while intubating the patient awake. The safety of this technique has been demonstrated. In a clinical controlled trial, Uday et all., evidenced the quality of the anesthesia which may even be superior to the mucosal instillation technique to block the superior laryngeal nerve. (8)

FIGURE 2. "Paramedial laryngeal image.
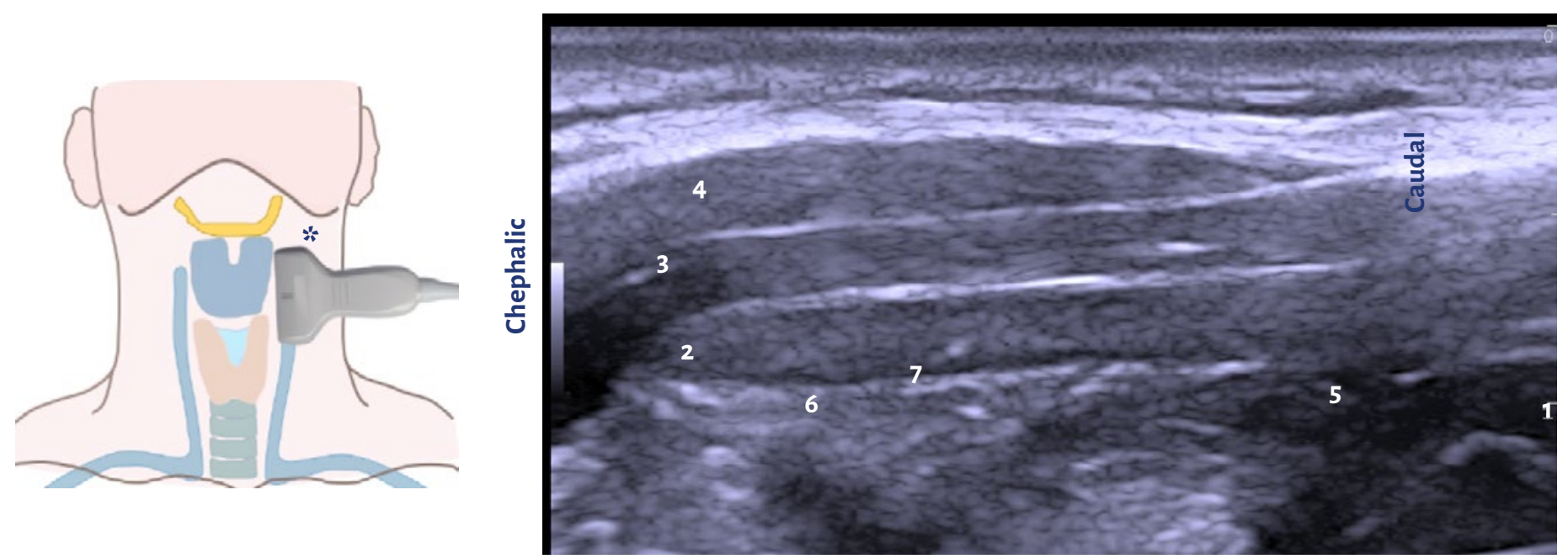

(1) Grater hyoid horn; (2) sternocleidomastoid muscle; (3) omohyoid muscle; (4) thyrohyoid muscle; (5) thyroid cartilage; (6) thyrohyoid membrane; (7) application target. souRCE. Authors. 
Another scenario in which this block may be useful is in tracheostomy with the patient awake and under local anesthesia. Successful cases with this technique have been reported; however, the skin anesthesia by planes may be insufficient, in addition to being poorly tolerated, results in patient dissatis- faction, pain and coughing, and even complications that may present in up to $16.2 \%$ of the cases; these complications include losing the airway and failed surgical technique. (9) For these reasons, it is extremely important to ensure adequate conditions for analgesia of the patient undergoing awake tracheostomy, and this makes the ultrasound-guided superior airway block a safe and highly successful procedure.

In conclusion, the use of ultrasound guidance to block the superior laryngeal nerve may be a valuable tool for the management of anticipated difficult airways.

FIGURE 3. Cadaveric model.

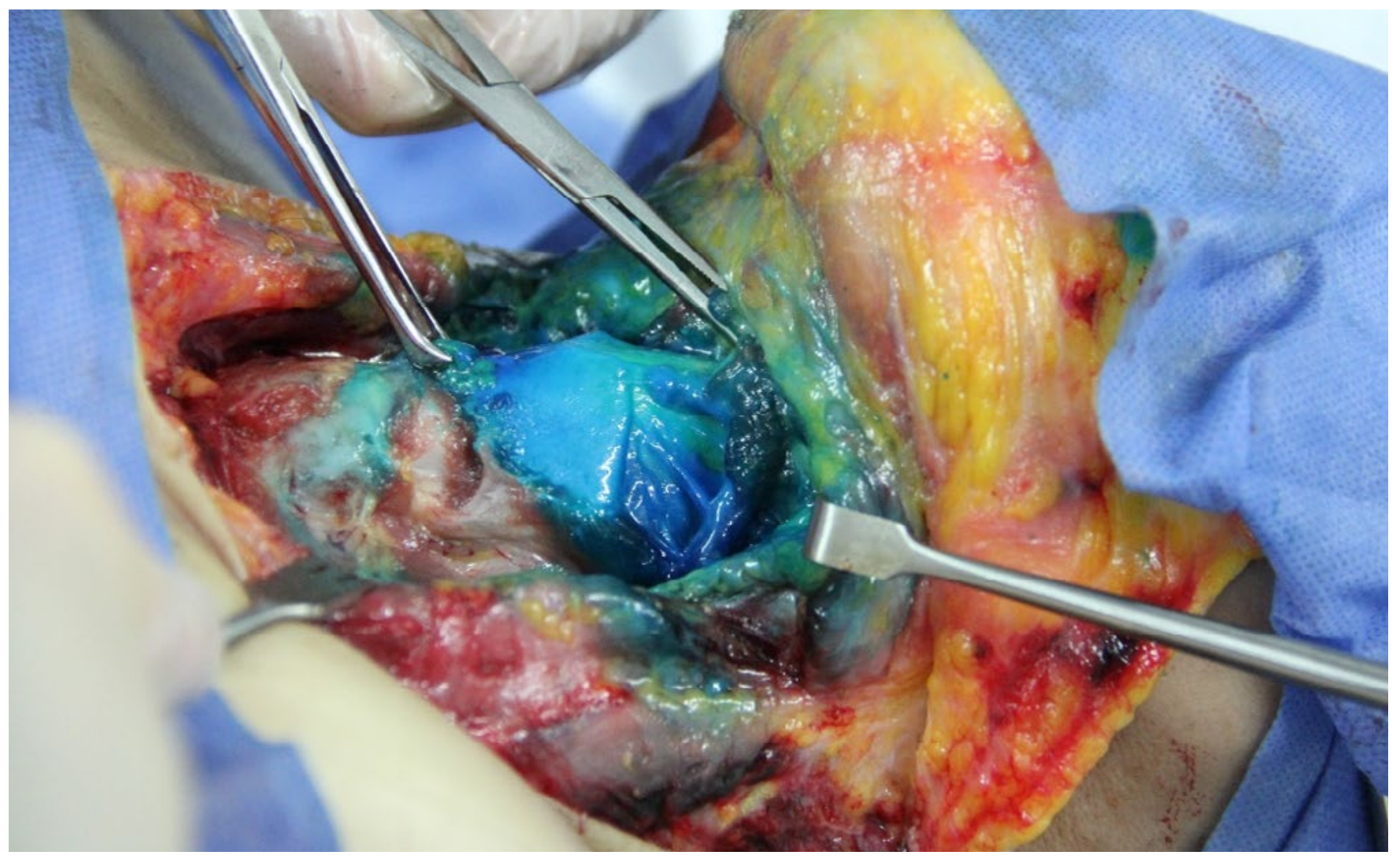

A $1 \mathrm{~cm}^{3}$ of methylene blue injection is administered under ultrasound guidance, in order to block the internal branch of the bilateral superior laryngeal nerve (ibSLN). The spread of the methylene blue over the thyrohyoid membrane is observed, blocking the ibSLN. SOURCE. Authors.

\section{ETHICAL RESPONSIBILITIES}

\section{Protection of humans and animals.}

The authors declare that the procedures performed were compliant with the ethical standards of the human experimentation committee and consistent with the World
Medical Association and the Declaration of Helsinki.

\section{Confidentiality of the information.}

The authors declare that they followed the institutional protocols on the publication of patient data.

\section{Right to privacy and informed consent}

The authors obtained the informed consent from all patients and/or subjects mentioned in this article. The corresponding author is the custodian of these documents. 


\section{ACKNOWLEDGEMENTS}

\section{Authors' contribution}

YCEO, MAZB, and DCC participated in the imaging obtaining, literature search and analysis, as well as the complete writing of the manuscript.

\section{Study assistance}

None declared.

\section{Financial support and sponsorship}

The authors did not receive any sponsorship to produce this article.

\section{Conflicts of interest}

The authors have no conflicts of interest to disclose.

\section{Presentations}

None declared.

\section{Appreciation}

None declared.

\section{REFERENCES}

1. Cook TM, Woodall N, Frerk C, Fourth National Audit Project. Major complications of airway management in the UK: Results of the Fourth National Audit Project of the Royal College of Anaesthetists and the Difficult Airway Society. Part 1: anaesthesia. Br] Anaesth. 2011;106:61731. doi: http://doi.org/10.1093/bja/aero58

2. Joffe AM, Aziz MF, Posner KL, Duggan LV, Mincer SL, Domino KB. Management of difficult tracheal intubation: A closed claims analysis. Anesthesiology. 2019;131(4):818-29. doi: http:// doi.org/10.1097/ALN.0000000000002815

3. Law JA, Broemling N, Cooper RM, et al. The difficult airway with recommendations for management--part 2--the anticipated difficult airway. Can ] Anaesth. 2013;60(11):1119-38. doi: http://doi.org/10.1007/s12630-013-0020-x

4. Ahmad I, El-Boghdadly K, Bhagrath R, et al. Difficult airway society guidelines for awake tracheal intubation (ATI) in adults. Anaesthesia. 2020;75:509-28. doi: http://doi.org/10.1111/ anae.14904
5. Langeron O, Bourgain JL, Francon D, Amour ], Baillard C, Bouroche G, et al. Difficult intubation and extubation in adult anaesthesia. Anaesth Crit Care Pain Med. 2018;37(6):639-51. doi: http://doi.org/10.1016/j. accpm.2018.03.013

6. Fang $\mathrm{CH}$, Friedman R, White PE, Mady L], Kalyoussef E. Emergent Awake tracheostomy-The five-year experience at an urban tertiary care center. Laryngoscope. 2015;125:2476-9. doi: http://doi.org/10.1002/lary.25348

7. Standring S. Head a neck: overview and surface anatomy. En: Standring S, editor, Gray's Anatomy. Edición 41. Londres; 2016. p. 399-415.

8. Ambi US, Arjun BK, Masur S, Endigeri A, Hosalli V, Hulakund SY. Comparison of ultrasound and anatomical landmark-guided technique for superior laryngeal nerve block to aid awake fibre-optic intubation: A prospective randomised clinical study. Indian ] Anaesth. 2017;61:463-8. doi: http://doi.org/10.4103/ija.IJA_74_17

9. Maiya B, Smith HL. Failed tracheostomy under local anaesthesia... plan B? ] Laryngol Otol. 2006;120(10):882-4. doi: http://doi. org/10.1017/So022215106001836 